\title{
MEASURING ELEMENTS OF PSYCHOLOGICAL LITERACY IN STUDENTS: COMPARING GENDER, EDUCATIONAL LEVEL AND DISCIPLINE
}

\author{
J. Taylor, S. Coady \\ Bournemouth University (UNITED KINGDOM)
}

\begin{abstract}
The term 'psychological literacy' relates to an individual's ability to apply an understanding of psychology to their everyday personal, social and work lives. An understanding of psychology can be useful for students across all disciplines, however there is little research comparing levels of psychological literacy across students from other disciplines. We aimed to explore the levels of psychological literacy across discipline, gender and education. Data was collected from a wide range of students and the sample comprised 128 females and 59 males, aged between 17 to 52 years (mean 23 years) studying pre-degree, undergraduate and postgraduate courses. Students came from five disciplines: Business, Health, IT, Law and Psychology. Statistical tests compared students across five dimensions of psychological literacy. There were many unexpected findings, for example there was a significant gender difference, such that females scored significantly lower psychological literacy than males. Regarding perceived knowledge of basic concepts and principles in psychology, Business students showed significantly higher levels, rather than psychology students. Although the results are surprising the sample was skewed with the majority female, at undergraduate level, and studying psychology. In the next stage of research, further data is being collected from the under-represented demographic groups so that we can ascertain whether these findings are consistent.
\end{abstract}

Keywords: psychological literacy, demographic, disciplines, undergraduates, diversity, ethics, confidence

\section{INTRODUCTION}

Around 10 years ago a number of key academic books and articles were published and 'psychological literacy' became a recognized term in psychology education [1,2]. The term 'psychological literacy' relates to an individual's ability to apply an understanding of psychology to their everyday personal, social and work lives. Psychological literacy has been defined [3] as, "Applying psychological principles to personal, social, and organizational issues in work, relationships, and the broader community" and "Being insightful and reflective about one's own and others' behavior and mental processes" (p. 11). Although naturally the greatest development and application of psychological literacy has been within psychology education, it has been proposed [4] that an understanding of psychology is relevant to students across other disciplines. Indeed, many undergraduate courses already include elements of psychology and develop psychological literacy; these include medicine, teacher training, media, law, biology, health and business. In this introduction, we will highlight some examples to show how psychological literacy can be usefully applied across disciplines and within society. We will then provide some example activities used within psychology. In the final section of this introduction we will identify some key ways that psychological literacy has been measured.

\subsection{Psychological literacy for all}

Psychological literacy can play an important role in diverse parts of society and if all students have an understanding of psychology this can affect our future work force. For example, psychological literacy can help support teachers, doctors, managers, health professionals, economists, engineers, IT professionals, in their understanding of and interactions with people. Benefits could include clearer communication with patients, customers and clients, better teaching and learning, more scientific evaluation of evidence, and the design and implementation of computing systems and software that is more user-friendly. This article proposes that an understanding of psychology is relevant to develop in students across all disciplines. According to [5], psychology as a discipline has much to offer for the public good as many of the problems in society today relate to human behavior (e.g. work stress, environmental damage, obesity, addiction to alcohol, drugs and technologies). So for example, knowledge regarding the biological basis of stress can help individuals to understand why and how 
different techniques work to alleviate stress. Regarding societal issues, evidence-based research in psychology can be used to show how interventions lead to improved health or well-being.

Psychological literacy is about more than understanding and applying psychological knowledge, transferable skills can also be developed through an understanding of psychology. For example, if students have opportunities to acquire and reflect on metacognitive capacities, they will be better able to connect psychological science to solutions in their own lives. Potentially, all students may benefit from an understanding of metacognition; illustrating to students how humans learn can help students to reflect upon their own learning preferences and style, it can help to develop effective techniques for note-taking, revising and sitting exams as well as in the longer term to develop a capacity for life-long learning. Communication and group skills can be improved if students have some understanding of the processes that enhance and degrade these skills (e.g. groupthink, social loafing, interpreting nonverbal cues). An understanding of the research process and the development of research skills used in psychology can be useful for students of non-scientific disciplines. The ability to relate theory, hypotheses, research methods and results to their implications is helpful for any activity involving humans. For example, highlighting the potential application of psychological findings allows students to fully appreciate the contribution that psychology can make to their working lives (e.g. understanding a research report and statistics). An understanding of psychology can also help students better understand their personal lives (e.g. help to understand their own individual development and growth). Being critical about the way statistics are used can help understand reports in the media and in advertising.

\subsection{Examples where activities to develop psychological literacy have been embedded within psychology curricula}

Since 2007, when an influential report [6] called for all UK Psychology degrees to include psychological literacy, there has been increasing interest in developing psychological literacy within the UK from the psychology community. Since then, academics have been introducing the concept to their students, however there have been relatively few resources published. Recently a compendium of case studies was collated [7] to address this need. In this section, we will now review some examples of practical activities that have been used within psychology.

The majority of case studies in the compendium discuss the ways that developing psychological skills can enhance future employability The benefits of including discussions of employability at all levels of the degree and not just in the final year are emphasized. Over half of the case studies report the many psychological skills developed from students taking a placement or similar activity such as volunteering or work based learning. Psychological literacy was mainly covered at level six and mainly in optional units or voluntary extra-curricular activities, therefore missing out on the potential for value to all students. One of the key suggestions from [7], was that psychological literacy should be embedded throughout a degree to realize the developmental benefits and ensure all students come into contact with the concept. Activities to develop psychological literacy were mainly observed in social and developmental psychology and applied psychology units (such as occupational psychology and mental health); there were less examples from biological and cognitive psychology. The majority of activities occurred in units that developed transferable skills, for example, experiential learning, psychological enquiry, psychology in everyday life and employability. Teaching and learning activities were varied and included many interactive techniques, such as group work, and enquiry-based or project-based learning. One of the case studies highlights the many positive outcomes from using activities where students from different year groups collaborate together in a peer mentoring scheme. Another example asked students to evaluate alternative courses of action when presented with a novel problem and to design an intervention or solution. The majority of case studies address the key psychological attribute of reflection, e.g. activities relating to the development of a skeptical approach to psychology research when it is reported across various media. Not all units covering psychological literacy activities were assessed. The level of assessment varied and some were novel, such as asking students to present in the Pecha Kucha format.

\subsection{Measurements of psychological literacy}

Nine attributes that psychology graduates should display have been identified [3] and these are often used as measures of the concept of psychological literacy. These are: 1. having a well-defined vocabulary and knowledge of the subject matter of psychology; 2 . valuing the intellectual challenges required to use scientific thinking and the disciplined analysis of information to evaluate alternative courses of action; 3 . taking a creative and amiable sceptical approach to problem solving; 4 . applying 
psychological principles to personal, social, and organizational issues in work, relationships, and the broader community; 5 . acting ethically; 6 . being competent in using and evaluating information and technology; 7 . communicating effectively in different modes and with many different audiences; 8. recognizing, understanding, and fostering respect for diversity; and 9. being insightful and reflective about one's own and others' behaviour and mental processes. Since this research, [8] identified two further attributes: global citizenship and a 'supporting and caring' attribute.

\subsection{Rationale}

The materials used in this study were adapted with permission from those developed by researchers based in Australia [8]. Selected scales from that study were used with the aim to pilot the materials before a larger cross-sectional study is conducted in the UK. As the study is exploratory, no hypotheses were predicted, however it would be expected that students with advanced educational qualifications would develop higher levels of psychological literacy and that students studying psychology courses would have higher levels, than those studying other disciplines.

\section{METHODOLOGY}

\subsection{Design}

The research employed a within-subjects design to explore differences in demographic factors for scores on five psychological literacy measures. Responses from five questionnaires were scored using the standardized scales of measurement and totals produced.

\subsection{Participants}

Adverts were placed on university websites and through social media and 233 students initially responded, but after incomplete responses were removed, there were 187 fully completed surveys. The sample comprised 128 females and 59 males, with ages ranging from 17 to 52 years (mean 23 years). Students came from 17 different courses and these were combined into five disciplines: 'Business' included students on management, marketing, accounting and finance courses $(n=16)$; 'Health' included students on social care, sport and nutrition courses $(n=20)$; 'IT students included engineering, design and software courses $(n=19)$; 'Law' included students on journalism, media and communication courses $(n=14)$ although the majority were from Psychology, which included counselling students $(n=118)$. Education level was categorized into pre-degree $(n=23)$, undergraduate degree $(n=156)$ and post-graduate $(n=8)$.

\subsection{Materials}

Questions requesting demographic information and established questionnaires were uploaded to the online survey site Qualtrics. Five measures of psychological literacy were collected, as described below.

\subsubsection{Integrity}

The Integrity Scale [9] was used to measure the dimension of psychological literacy to act ethically. Participants responded to 18 items on a 5-point Likert scale, ranging from 1 (strongly disagree) to 5 (strongly agree). Total scores could range from 18 to 90 . An example item was, 'Lying is sometimes necessary to accomplish important, worthwhile goals'.

\subsubsection{Confidence in evaluating and using information and technology}

The Information Literacy Self-Efficacy Scale [10], was used to measure the dimension of psychological literacy relating to competency in using and evaluating information and technology. The question was worded, 'I feel confident and competent to...' and then 17 items were listed and measured on a sevenpoint Likert scale, from 7 (almost always true) to 1 (almost never true). Total scores could range from 17 to 119 . An example item was, 'synthesize newly gathered information with previous information'.

\subsubsection{Student's perceptions of their own psychological literacy}

In the same way as has been used in previous research [8], students were asked if they were aware of the concept of psychological literacy, and then following a definition of psychological literacy, they were asked to indicate on a scale of 1 to 100 , 'How developed is your own psychological literacy?'. 


\subsubsection{Self-perceived competency of basic concepts relating to psychological literacy}

Nine items, based on McGovern's psychological literacy dimensions, were used to provide a more complete measure. These have been used in previous research [11]. Participants were asked to rate their competency against each of the dimensions using a four-point Likert scale (where $1=$ nonexistent, $2=$ poor, 3 = reasonable, and $4=$ excellent). Total scores could range from 9 to 36 . The question asked, "At this point in your education, how would you rate your knowledge of basic concepts/principles in Psychology?".

\subsubsection{Experience of interactions with people from diverse backgrounds}

The Interactional Diversity Scale [12] was used to measure the dimension of psychological literacy relating to understanding and fostering respect for diversity. A set of 7 statements were provided and participants responded to a 4-point scale, where 1 represented never, to 4 representing very often. Total scores could range from 7 to 28. An example item is, "Have you had serious discussions with students whose race or ethnic background were very different than yours?".

\subsection{Procedure}

Participants completed the online survey in their own time and in their preferred location. At the start of the survey, participants were asked to read the information sheet and to read and sign the consent form. After this had been completed, the participant completed the online survey. The participants were debriefed and given the researchers details to contact if needed.

\section{RESULTS}

\subsection{Descriptive data}

As can be seen from Table 1, Business students scored lower than all other disciplines on the first three scales (integrity, confidence in evaluating information and perception of psychological literacy), however they scored highest on knowledge of psychological concepts. Health students perceived their psychological literacy as higher than all other disciplines. Disciplines scored similarly on their experience interacting with people from diverse backgrounds. Surprisingly, psychology students did not score the highest on the psychological variables, but only on confidence in evaluating information.

Table 1. Mean scores for each discipline on dimensions of psychological literacy

\begin{tabular}{l|c|c|c|c|c}
\hline \hline & $\begin{array}{c}\text { Integrity } \\
\text { scale }\end{array}$ & $\begin{array}{c}\text { Confidence } \\
\text { in evaluating } \\
\text { information }\end{array}$ & $\begin{array}{c}\text { Perception of } \\
\text { psychological } \\
\text { literacy }\end{array}$ & $\begin{array}{c}\text { Knowledge } \\
\text { of } \\
\text { psychological } \\
\text { concepts }\end{array}$ & $\begin{array}{c}\text { Interacting } \\
\text { with people } \\
\text { from diverse } \\
\text { backgrounds }\end{array}$ \\
\hline Business & 57.63 & 77.31 & 55.50 & 32.94 & 20.25 \\
\hline IT & 60.74 & 87.26 & 58.16 & 30.21 & 19.00 \\
\hline Health & 56.95 & 89.05 & 64.65 & 31.5 & 19.05 \\
\hline \hline Law & 60.00 & 90.93 & 61.07 & 31.5 & 19.43 \\
\hline \hline Psychology & 59.29 & 90.97 & 58.56 & 29.5 & 20.04 \\
\hline \hline
\end{tabular}

As can be seen from Table 2, as students moved through their education they indicated higher levels of most of the dimensions of psychological literacy. However, the results for the dimension 'Knowledge of psychological concepts' showed the opposite pattern.

Table 2. Means scores for each educational level on dimensions of psychological literacy

\begin{tabular}{c|c|c|c|c|c}
\hline \hline & $\begin{array}{c}\text { Integrity } \\
\text { scale }\end{array}$ & $\begin{array}{c}\text { Confidence } \\
\text { in evaluating } \\
\text { information }\end{array}$ & $\begin{array}{c}\text { Perception of } \\
\text { psychological } \\
\text { literacy }\end{array}$ & $\begin{array}{c}\text { Knowledge } \\
\text { of } \\
\text { psychological } \\
\text { concepts }\end{array}$ & $\begin{array}{c}\text { Interacting } \\
\text { with people } \\
\text { from diverse } \\
\text { backgrounds }\end{array}$ \\
\hline \hline
\end{tabular}




\begin{tabular}{l|l|l|l|l|l}
\hline \hline Pre-degree & 61.13 & 80.04 & 53.74 & 31.04 & 19.35 \\
\hline Degree & 58.62 & 90.46 & 60.01 & 30.19 & 19.74 \\
\hline Postgraduate & 62.63 & 91.25 & 56.75 & 28.75 & 22.25 \\
\hline \hline
\end{tabular}

As can be seen from Table 3, there appeared to be very few gender differences, the only observable difference was for the perception of psychological literacy scale.

Table 3. Means scores for males and females on dimensions of psychological literacy

\begin{tabular}{l|c|c|c|c|c}
\hline \hline & $\begin{array}{c}\text { Integrity } \\
\text { scale }\end{array}$ & $\begin{array}{c}\text { Confidence } \\
\text { in evaluating } \\
\text { information }\end{array}$ & $\begin{array}{c}\text { Perception of } \\
\text { psychological } \\
\text { literacy }\end{array}$ & $\begin{array}{c}\text { Knowledge } \\
\text { of } \\
\text { psychological } \\
\text { concepts }\end{array}$ & $\begin{array}{c}\text { Interacting } \\
\text { with people } \\
\text { from diverse } \\
\text { backgrounds }\end{array}$ \\
\hline Males & 59.37 & 89.56 & 60.29 & 29.54 & 19.51 \\
\hline Females & 58.97 & 89.05 & 58.55 & 30.55 & 19.94 \\
\hline \hline
\end{tabular}

\subsection{Analysis of data for each dimension of psychological literacy}

Statistical analyses were conducted using a series of between-subjects ANOVA tests and the results are discussed separately for each of the five dimensions.

\subsubsection{Integrity}

There were no differences between discipline or gender, but a significant effect for educational level $(F=6.055, p=0.003$, d.f. 2,186$)$. As can be seen from Table 2, the scores of students increased as they progressed through the educational system.

\subsubsection{Confidence in evaluating information and using information and technology}

There was a significant effect according to discipline and differences in means $(F=2.87, p=0.025$, df 4,186). As shown in Table 1, Business students scored significantly lower than all other disciplines. While Psychology students showed the highest level, this was not statistically significant.

\subsubsection{Student's perceptions of their own psychological literacy}

There were no significant differences across discipline, age or education, but there was a significant gender difference $(F=4.805, p=0.03$, d.f. 1,186). As can be seen from Table 3 , females scored significantly lower (mean=58.5) than males (mean=60.3).

\subsubsection{Self-perceived competency of basic concepts relating to psychological literacy}

Discipline significantly differentiated high and low levels of psychological literacy $(F=3.244, p=0.014$, d.f. 4,186). As illustrated in Table 1, Business students show the highest levels, rather than psychology students.

\subsubsection{Experience of interactions with people from diverse backgrounds}

There were no significant differences between students on this dimension of psychological literacy; confirming the very similar scores for this measure shown in Tables 1 to 3 .

\section{CONCLUSIONS}

The results are surprising in that psychology students did not show higher levels of many of the dimensions included within the concept of psychological literacy. Responses to the 'integrity' scale, measuring ethical beliefs, showed no differences between discipline, age, or gender but a significant effect for educational level; such that post-graduate students indicated higher scores than both predegree and undergraduate students. Responses to a 'confidence in evaluating information' scale showed that Business studies students scored significantly lower than all other disciplines; and while Psychology students showed the highest level, this was not statistically significant. Analysis of student's perceptions of their own psychological literacy showed no significant differences across 
discipline or education, but there was a significant gender difference, such that females scored significantly lower than males; which conflicts with much of the literature. Regarding perceived knowledge of basic concepts and principles in psychology, Business studies students showed the highest levels, rather than psychology students. This is in contrast with recent research [13], which showed that psychological literacy did differentiate students by both discipline and year of enrolment; however, in that study the disciplines were all from the health sector (e.g. human resource management, psychology and speech pathology).

A major limitation with this study was that the data were skewed as the majority of the sample were female, at undergraduate level and studying psychology. Further data will now be collected from the under-represented demographic groups to identify whether these findings are generalizable.

\section{ACKNOWLEDGEMENTS}

Thanks are expressed to Bournemouth University Centre for Excellence in Learning (CEL) for financial support to collect the data on which this paper is based.

\section{REFERENCES}

[1] D. F. Halpern (Ed.). "Undergraduate Education in Psychology: A Blueprint for the Future of the Discipline". Washington, DC: American Psychological Association, 2010.

[2] J. Cranney, \& D. S. Dunn (Eds.), "The Psychologically Literate Citizen: Foundations and global perspectives". New York: Oxford University Press, 2011.

[3] T.V. McGovern, L. Corey, J. Cranney, W.E. Dixon, J.D. Holmes, J.E. Kuebli, K.A. Ritchey, R.A. Smith \& S.J. Walker, "Psychologically literate citizens". In D. F. Halpern (Ed.), Undergraduate Education in Psychology: A Blueprint for the Future of the Discipline (pp. 9-27). Washington, DC: American Psychological Association, 2010.

[4] J. Taylor, "Psychological literacy for all: an overview of this 'literacy' and how it is relevant for students of all disciplines", IATED Conference, Majorca, 1-3 July 2019.

[5] J. Cranney, "Why psychological literacy is relevant to all psychology graduates, regardless of career destination", ICOPE Conference, University of Dhaka, Bangladesh, 22 - 23 March, 2019.

[6] A. Trapp, P. Banister, J. Ellis, R. Latto, D. Miell, and D. Upton, "The Future of Undergraduate Psychology in the United Kingdom". York: Higher Education Academy, 2011. Retrieved $24^{\text {th }}$ April 2019 from https://www.heacademy.ac.uk/knowledge-hub/future-undergraduatepsychology-united-kingdom

[7] J. Taylor and J. Hulme, "Introducing a compendium of psychological literacy case studies: Reflections on psychological literacy in practice", Psychology Teaching Review, vol. 21, no. 2, pp. 25-34, 2015.

[8] L. D. Roberts, B Heritage, \& N. Gasson, "The measurement of psychological literacy: a first approximation“, Frontiers in Psychology, vol. 6, article 105, 2015.

[9] V. Schlenker, "Integrity and character: implications of principled and expedient ethical ideologies", Journal of Social Clinical Psychology, vol. 27, pp. 1078-1125, 2008.

[10] S. S. Kurbanoglu, B. Akkoyunlu and A. Umay, "Developing the information literacy self-efficacy scale", Journal of Documentation, vol. 62, no. 6, pp. 730-743, 2006.

[11] A. Chester, L.J. Burton, S. Xenos, and K. Elgar, "Peer mentoring: supporting successful transition for first year undergraduate psychology students", Aust. J. Psychology, vol. 65, pp. 30-37, 2013.

[12] S. Hu, and G. D. Kuh, "Diversity experiences and college student learning and personal development", Journal of College Student Development, vol. 44, pp. 320-334, 2003.

[13] B. Heritage, L. D. Roberts \& N. Gasson, "Psychological literacy weakly differentiates students by discipline and year of enrolment", Frontiers in Psychology, vol. 7, article 162, 2016. 